\title{
Óxido de cálcio e Lactobacillus buchneri NCIMB 40788 na ensilagem de cana-de-açúcar in natura ou queimada
}

\author{
Gustavo Rezende Siqueira ${ }^{1}$, Ruben Pablo Schocken-Iturrino ${ }^{2}$, Anna Paula de Toledo Piza \\ Roth $^{3}$, Felipe Nogueira Domingues ${ }^{4}$, Antonio Sergio Ferraudo ${ }^{5}$, Ricardo Andrade Reis ${ }^{6}$ \\ ${ }^{1}$ Apta - Pólo Regional da Alta Mogiana - Av. Rui Barbosa, s/no, Caixa Postal 35, 14770-000, Colina -SP; Programa de Pós-graduação em \\ Zootecnia da Faculdade de Ciências Agrárias e Veterinárias - Unesp - Campus de Jaboticabal - SP. \\ 2 Departamento de Patologia Veterinária - Faculdade de Ciências Agrárias e Veterinárias - Unesp - Campus de Jaboticabal - SP. Pesquisador \\ do CNPq. \\ ${ }^{3}$ Departamento de Zootecnia - Faculdade de Ciências Agrárias e Veterinárias - Unesp - Campus de Jaboticabal - SP. \\ ${ }^{4}$ UFPA/Faculdade de Medicina Veterinária/Campus de Castanhal. \\ 5 Departamento de Ciências Exatas - Faculdade de Ciências Agrárias e Veterinárias - Unesp - Campus de Jaboticabal - SP. \\ ${ }^{6}$ Departamento de Zootecnia - Faculdade de Ciências Agrárias e Veterinárias - Unesp - Campus de Jaboticabal - SP. Pesquisador do CNPq \\ Membro do INCT/CA.
}

RESUMO - Objetivou-se avaliar os efeitos da inclusão de óxido de cálcio (CaO) e/ou L. buchneri (LB) sobre as perdas e alterações químicas de silagens de cana-de-açúcar in natura ou queimada. Foram avaliadas silagens de cana-de-açúcar in natura ou queimada produzidas sem aditivo; com Lactobacillus buchneri; com óxido de cálcio equivalente 1\% da matéria natural; ou com a associação do L. buchneri e do óxido de cálcio. O delineamento experimental utilizado foi o inteiramente casualizado em esquema fatorial $(2 \times 4)$, considerando fatores a queima (presença ou ausência) e o uso de aditivos (L. buchneri, óxido de cálcio e sua associação), cada um avaliado com três repetições. O óxido de cálcio foi mais eficiente em reduzir a variação no teor de matéria seca tanto nas silagens de cana-de-açúcar in natura quanto na queimada. Nas silagens de cana-de-açúcar sem aditivos, maiores recuperações de matéria seca foram observadas quando a ensilagem foi feita com cana in natura (63,5\%) em comparação à cana queimada (46,8\%). Todavia, quando utilizados aditivos, não houve diferenças entre as silagens de canade-açúcar in natura e queimada. A presença de óxido de cálcio foi o fator que promoveu maior diferença entre as silagens. O óxido de cálcio é eficiente em reduzir as perdas e as alterações químicas na ensilagem de cana-de-açúcar, tanto in natura quanto queimada. O L. buchneri atua eficientemente em silagens de cana-de-açúcar queimada. Silagens de cana-de-açúcar queimada são mais propensas às perdas que as de cana-de-açúcar in natura.

Palavras-chave: aditivos, análise multivariada, fermentação, inoculante bacteriano, silagem

\section{Calcium oxide and Lactobacillus buchneri NCIMB 40788 in the ensiling of in natura or burned sugar cane}

\begin{abstract}
The objective of this trial was to evaluate the effects of the inclusion of calcium oxide (CaO) and/or $L$. buchneri (LB) on the losses and chemical composition changes of in natura and burned sugar cane silages. Silage treatments were: in natura sugar cane without additive (IS), with Lactobacillus buchneri (ISLB), with calcium oxide (ISCaO) equivalent to $1 \%$ of natural matter, and the combination of $\mathrm{LB}$ and $\mathrm{CaO}$ (ISLBCaO). Experimental design was completely randomized in a factorial scheme $(2 \times 4)$ considering status (burned or not) and additives $(\mathrm{LB}, \mathrm{CaO}$ and $\mathrm{LB}+\mathrm{CaO})$ with three replications per treatment. Dry matter variation was lower for in natura and burned silages treated with $\mathrm{CaO}$; regardless of the LB presence, the mean difference was 5.85 percentage units. In sugar cane silages without additives, higher dry matter recoveries were observed when the plant was ensiled with in natura silage (63.5\%) compared with burned silage (46.8\%). However, when additives ( $\mathrm{CaO}$ and $\mathrm{LB}$ ) were used, no significant differences occurred between the in natura and burned silage treatments. The presence of calcium oxide was the factor that provided the greatest discrimination among the data. Calcium oxide is effective in reducing losses and chemical changes on the in natura and burned silages. The L. buchneri acts effectively on burned sugar cane silages, and the latter are more susceptible to losses than those of in natura sugar cane.
\end{abstract}

Key Words: additives, fermentation, inoculants, multivariate analysis, silage 


\section{Introdução}

A maioria das espécies de leveduras atua preferencialmente em condições de aerobiose, todavia algumas podem manter a população em condições de anaerobiose fermentando açúcares solúveis e gerando etanol (Walker, 1998), condições semelhantes às apresentadas na ensilagem da cana-de-açúcar. A fermentação por leveduras propicia, segundo McDonald et al. (1991), perdas quantitativas do substrato fermentado que podem chegar a $48,9 \%$. Nesse sentido, a redução das perdas de matéria seca advindas do controle de leveduras durante a ensilagem da cana-deaçúcar é o principal alvo das pesquisas sobre esse assunto (Pedroso et al., 2005; Siqueira et al., 2007a).

A utilização de aditivos é uma alternativa para redução das perdas de matéria seca e obtenção de silagens de canade-açúcar com melhor valor nutritivo (Pedroso et al., 2007). Nussio \& Schmidt (2004) apontaram como aditivo promissor a ser utilizado na ensilagem da cana-de-açúcar o Lactobacillus buchneri, uma bactéria heterofermentativa que converte açúcares solúveis e ácido lático em ácido acético (Oude Elferink et al., 2001). Segundo Moon (1983), o ácido acético tem efeito inibidor sobre o crescimento de leveduras.

Outro aditivo, de utilização mais recente na ensilagem de cana-de-açúcar, é a cal com suas variações, ou seja, hidróxido e óxido de cálcio. Santos et al. (2008) observaram redução no teor de etanol de 4,78 para 0,38\% da MS e das perdas de matéria seca, de 34,3 para 16,9\%, com a utilização de $1 \%$ de óxido de cálcio e a possível explicação para esse efeito foi a redução da atividade de água, com consequente inibição do crescimento de leveduras. Balieiro Neto et al. (2007) também constataram efeito positivo da ação do óxido de cálcio na ensilagem da cana-de-açúcar, tanto nas fases de fermentação quanto durante a exposição aeróbia.

Outra estratégia apropriada para reduzir as perdas na ensilagem é a combinação de aditivos, que é uma linha crescente em países da Europa e nos EUA. Siqueira et al. (2007a,b) avaliaram a associação do L. buchneri com o hidróxido de sódio e constataram efeito sinérgico da atuação dos aditivos, com redução significativa das perdas por gases, elevação da recuperação de MS e manutenção do valor nutritivo mais próximo da cana-de-açúcar no momento da ensilagem.

A literatura é escassa em informações sobre o uso do óxido de cálcio e, principalmente sobre a associação desse aditivo com o L. buchneri na ensilagem da canade-açúcar.

Objetivou-se com a realização deste trabalho avaliar os efeitos da inclusão do óxido de cálcio e/ou do L. buchneri sobre as perdas e alterações químicas em silagens de cana-de-açúcar in natura ou queimada.

\section{Material e Métodos}

A cana-de-açúcar (Saccharum officinarum L.) utilizada foi a variedade IAC 86-2480, produzida no Pólo Regional de Desenvolvimento dos Agronegócios da Alta Mogiana APTA Regional de Colina. A colheita mecânica foi realizada em setembro de 2006, quando a cana-de-açúcar apresentava-se apta para o corte, com produção de $130 \mathrm{t}$ MV/ha aos 18 meses de crescimento vegetativo (cana-planta).

A forragem foi colhida utilizando-se ensiladeira modelo Menta Mit 3000, produzindo partícula de 1 a $3 \mathrm{~cm}$. A queima da cana foi realizada no final da tarde do dia anterior ao corte e a colheita dos colmos, no momento da ensilagem.

Os tratamentos consistiram da utilização do L. buchneri (LB) e do óxido de cálcio $(\mathrm{CaO})$ na ensilagem da cana-de-açúcar in natura (CI) e queimada (CQ). O delineamento experimental utilizado foi inteiramente casualizado em esquema fatorial considerando fatores a queima (presença ou ausência) e o uso de aditivos (sem aditivo, $\mathrm{LB}, \mathrm{CaO}$ e $\mathrm{LB}+\mathrm{CaO}$ ) com três repetições por tratamento, sendo: cana-de-açúcar in natura sem aditivo (CI), cana-de-açúcar in natura com L. buchneri (CILB), cana-de-açúcar in natura com óxido de cálcio (CICaO), cana-de-açúcar in natura com $L$. buchneri e óxido de cálcio (CILBCaO), cana-de-açúcar queimada sem aditivo (CQ), cana-de-açúcar queimada com L. buchneri (CQLB), cana-de-açúcar queimada com óxido de cálcio (CQCaO) e cana-de-açúcar queimada com L. buchneri e óxido de cálcio (CQLBCaO).

O microrganismo Lactobacillus buchneri (Cepa NCIMB 40788) utilizado é encontrado no inoculante comercial LalsilCana ${ }^{\circledR}$. O inoculante bacteriano foi aplicado na dose de $5 \times 10^{4} \mathrm{ufc} / \mathrm{g}$ de forragem fresca, que equivale a $2 \mathrm{~g}$ de inoculante diluído em 2 litros de água por tonelada de forragem fresca. O óxido de cálcio foi adicionado na dose de $1 \%$ da forragem, diluído em água na proporção de $1 \mathrm{~kg}$ para 4 litros de água e aplicado em dose equivalente a 40 litros da mistura por tonelada de forragem fresca. Quando realizada a aplicação dos dois aditivos, primeiro procedeu-se à adição do óxido de cálcio e depois do Lactobacillus buchneri.

Como silos experimentais foram utilizados baldes de plástico com capacidade de 7 litros, munidos de tampas com válvulas de "Bunsen” para permitir o escape do gás e no fundo dos silos foram colocados $2 \mathrm{~kg}$ de areia seca, separada da forragem por uma tela e um tecido de náilon, para quantificação do efluente produzido. 
Foi determinado o volume de cada silo experimental, descontando-se o espaço ocupado pela areia e pesou-se a quantidade de forragem para obter a massa específica. Nas silagens de cana-de-açúcar in natura, a massa específica obtida foi $500 \mathrm{~kg}$ de forragem $/ \mathrm{m}^{3}$ e, nas de cana-de-açúcar queimada, de $800 \mathrm{~kg}$ de forragem $/ \mathrm{m}^{3}$. Após a compactação da forragem, os silos foram vedados com fita adesiva, pesados e armazenados à temperatura ambiente.

Decorridos 60 dias de armazenamento, os silos foram novamente pesados, para determinação das perdas por gás e abertos (Jobim et al., 2007). Após a retirada da silagem o conjunto silo, areia, tela e tecido de náilon foram pesados para quantificação do efluente produzido, conforme descrito por Siqueira et al. (2007a).

Antes da ensilagem e após a aplicação dos aditivos, a forragem foi amostrada três vezes para cada tratamento. Cada amostra foi pesada e levada para estufa de ventilação forçada a $60^{\circ} \mathrm{C}$ durante 72 horas, para determinação do conteúdo de matéria seca.

Na abertura, após homogeneização da silagem, retiraram-se duas amostras de cada silo. Uma das amostras coletadas foi preparada segundo metodologia descrita por Kung Junior et al. (1984) para determinação do pH com o uso do potenciômetro. A outra amostra foi pesada e levada para estufa de ventilação forçada a $60^{\circ} \mathrm{C}$ durante 72 horas.

As amostras que foram levadas para estufa foram novamente pesadas, moídas em moinho de faca até o tamanho das partículas atingirem menos de $1 \mathrm{~mm}$ e armazenadas em potes de plástico, para posterior determinação dos teores de matéria seca (MS) e proteína bruta (PB) segundo AOAC (1990). A digestibilidade verdadeira in vitro da MS foi determinada segundo Robertson \& Van Soest (1981). O teor de fibra em detergente neutro (FDN) foi avaliado segundo a técnica descrita por Robertson \& Van Soest (1981) com as amostras submetidas à digestão em solução detergente por $40 \mathrm{~min}$ em autoclave a $111^{\circ} \mathrm{C}$ e $0,5 \mathrm{~atm}$ (Deschamps, 1999).

Foi determinada a variação dos parâmetros avaliados na abertura em relação ao momento da ensilagem, pela seguinte formula:

Variação = valor do parâmetro na abertura - valor do parâmetro na ensilagem;

Os dados foram analisados estatisticamente pelos procedimentos da análise de variância (PROC ANOVA) e as médias comparadas pelo teste Tukey a 5\% de significância de $5 \%$ utilizando-se o programa de SAS (1999).

Para compreender a estrutura multivariada contida no conjunto original de dados, as análises univariadas foram complementadas com as análises estatísticas exploratórias multivariadas de agrupamento por métodos hierárquico e não-hierárquico e componentes principais, que permitiram uma avaliação em conjunto de todas as variáveis desejadas (Hair et al., 2005). Utilizaram-se como variáveis as variações dos valores de $\mathrm{pH}, \mathrm{PB}, \mathrm{FDN}$, DVIVMS e as perdas (perdas por gases, produção de efluente e recuperação de MS). Para aplicação das análises multivariadas, o conjunto de dados original foi padronizado de modo que cada descritor passou a ter média nula e variância unitária. A análise de agrupamento por método hierárquico foi processada inicialmente por não se ter nenhuma informação a priori do número de grupos. Foi adotada a distância euclidiana como medida de semelhança e a ligação entre os grupos pelo método UPGMA (Unweighted Pair-Group Method using arithmetic Averages) Sneath \& Sokal (1973). A partir do número de grupos adotado na análise de agrupamento por método hierárquico, processou-se a análise de agrupamento por método não-hierárquico utilizando-se o algoritimo k-means (Hair et al., 2005), que complementa os resultados da análise anterior.

A análise de componentes principais condensou as informações originais em novas variáveis latentes que são os componentes principais denominados de autovetores construídos com os autovalores da matriz de covariância. Estes são combinações lineares das variáveis originais e foram considerados aqueles cujos autovalores forem superiores à unidade, pois retém informações relevantes (Kaiser, 1958). Foram avaliados a importância de cada componente e o poder discriminatório de cada variável (Ferraudo, 2006). Todas as análises multivariadas foram processadas no software Statistica v. 7.0 (Statsoft, 2004).

\section{Resultados e Discussão}

Os dados de composição bromatológica da cana-deaçúcar antes da ensilagem (Tabela 1) apresentaram valor nutritivo compatível com os observados na tabela de levantamento da composição química de alimentos de Valadares Filho et al. (2006). O teor de matéria seca (MS) observado na cana-de-açúcar in natura sem aditivo (37,2\%) foi superior ao observado por Valadares Filho et al. (2006) (28,5\%), o que pode ser atribuído ao fato de a cana-de-açúcar ter sido colhida aos 18 meses, propiciando maior amadurecimento.

Os teores de FDN e lignina da cana-de-açúcar ensilada in natura, sem aditivo, antes da ensilagem (Tabela 1) foram próximos aos observados por Valadares Filho et al. (2006), que foram em média 57,7 e 7,8\% na MS, respectivamente. A digestibilidade verdadeira in vitro da matéria seca (DVIVMS) também foi semelhante à observada por Valadares Filho et al. (2006), que obtiveram em média $54,15 \%$ da MS, enquanto neste estudo o valor observado foi de $53,0 \%$ da MS. 
Tabela 1 - Composição da cana-de-açúcar antes da ensilagem

\begin{tabular}{|c|c|c|c|c|c|c|c|c|}
\hline \multirow[t]{2}{*}{ Parâmetro } & \multicolumn{4}{|c|}{ In natura } & \multicolumn{4}{|c|}{ Queimada } \\
\hline & CI & LB & $\mathrm{CaO}$ & $\mathrm{LB}+\mathrm{CaO}$ & CQ & LB & $\mathrm{CaO}$ & $\mathrm{LB}+\mathrm{CaO}$ \\
\hline $\mathrm{pH}$ & 5,7 & 5,7 & 12,3 & 12,2 & 5,5 & 5,6 & 11,7 & 12,1 \\
\hline Proteína bruta (\% MS) & 2,63 & 2,70 & 2,03 & 2,02 & 2,9 & 2,97 & 2,54 & 2,27 \\
\hline Fibra em detergente neutro (\% MS) & 55,2 & 53,2 & 49,7 & 48,0 & 37,8 & 43,4 & 39,8 & 38,6 \\
\hline Fibra em detergente ácido (\% MS) & 50,9 & 48,9 & 42,7 & 33,4 & 35,2 & 40,5 & 35,0 & 31,0 \\
\hline
\end{tabular}

DVIVMS = digestibilidade verdadeira in vitro da MS.

Merecem destaque as mudanças promovidas pela queima e também as alterações químicas com a inclusão do óxido de cálcio. Com a queima, ocorre redução acentuada dos componentes fibrosos, devido à eliminação da palha, que é uma fração com altas concentrações de FDN, FDA e lignina e que pode elevar proporcionalmente a concentração de carboidratos não-fibrosos. Outros reflexos foram a redução dos teores de MS, que em média foi de três unidades percentuais, e o aumento da DVIVMS, que foi de aproximadamente nove unidades percentuais se comparadas todas as forragens de cana-de-açúcar queimada com a média das misturas da cana-de-açúcar in natura antes da ensilagem. Resultados semelhantes aos observados nesta pesquisa (Tabela 1) para o efeito da queima sobre as alterações na composição química da silagem foram observados por Siqueira et al. (2009).

A adição de óxido de cálcio à cana-de-açúcar promoveu redução dos componentes fibrosos, cujos valores foram mais expressivos quando esse aditivo foi usado em combinação com L. buchneri. Atribui-se a redução da fibra à solubilização, principalmente da hemicelulose, devido à presença do agente alcalinizante (CaO). Balieiro Neto et al. (2007) também constaram essas alterações com a adição de óxido de cálcio na cana-de-açúcar antes da ensilagem. Pires et al. (2006) avaliaram o efeito da inclusão de $\mathrm{NaOH}$ no bagaço de cana-de-açúcar nas doses de 0; 2,5; 5,0 e 7,5\% na MS nos tempos de 1, 3, 5 e 7 dias e notaram efeito significativo das doses, porém sem efeito do tempo de armazenamento. Afirma-se, desta forma, que os agentes alcalinos têm rápida atuação sobre a forragem, pois muitos efeitos do óxido de cálcio ocorreram antes da ensilagem. Jobim et al. (2007), em revisão sobre metodologias de avaliação de forragens conservadas, alertaram para a importância de se avaliar a forragem antes da ensilagem e compará-la às silagens produzidas para observação das alterações ocorridas durante o processo de armazenamento.

Em relação aos teores de MS, nas silagens com adição de óxido de cálcio, não houve diferença significativa da queima ( $\mathrm{P}>0,05)$, ao passo que, nas silagens sem esse aditivo, a cana-de-açúcar queimada propiciou silagens com menor teor de MS (Tabela 2). Nas silagens de cana-deaçúcar in natura adicionadas de L. buchneri (LB), os teores de MS foram inferiores aos daquelas tratadas com óxido de cálcio $(\mathrm{P}<0,05)$, enquanto, nas silagens controles, os valores foram intermediários e não diferiram $(\mathrm{P}>0,05)$ dos obtidos com a adição de L. buchneri e óxido de cálcio. Nas silagens de cana-de-açúcar queimada, apenas a adição de óxido de cálcio promoveu diferenças $(\mathrm{P}<0,05)$. A adição de $L$. buchneri não interferiu no teor de MS $(\mathrm{P}>0,05)$.

A variação no conteúdo de matéria seca não apresentou diferença significativa entre as silagens de cana-de-açúcar in natura ou queimada $(\mathrm{P}>0,05)$. O óxido de cálcio proporcionou redução da variação no teor de MS, independentemente da presença do L. buchneri (Tabela 2).

Tabela 2 - Teores médios de matéria seca (\%) e variação da matéria seca de silagens de cana-de-açúcar in natura ou queimada tratadas com óxido de cálcio $(\mathrm{CaO})$ e/ou L. buchneri

\begin{tabular}{|c|c|c|c|c|c|c|}
\hline \multirow{3}{*}{ Aditivos } & \multicolumn{3}{|c|}{ Matéria seca (\%) } & \multicolumn{3}{|c|}{ Variação no teor de $\mathrm{MS}^{1}$} \\
\hline & \multicolumn{2}{|c|}{ Cana-de-açúcar } & \multirow{2}{*}{ Médias } & \multicolumn{2}{|c|}{ Cana-de-açúcar } & \multirow{2}{*}{ Médias } \\
\hline & In natura & Queimada & & In natura & Queimada & \\
\hline Controle & $25,9 \mathrm{ABa}$ & $19,3 \mathrm{Bb}$ & 22,6 & $-11,3$ & $-13,3$ & $-12,3 \mathrm{~A}$ \\
\hline Lactobacillus buchneri (LB) & $24,8 \mathrm{Ba}$ & $21,3 \mathrm{Bb}$ & 23,0 & $-11,5$ & $-10,6$ & $-11,1 \mathrm{~A}$ \\
\hline Óxido de cálcio $(\mathrm{CaO})$ & $27,1 \mathrm{Aa}$ & $27,8 \mathrm{Aa}$ & 27,4 & $-7,7$ & $-5,2$ & $-6,4 \mathrm{~B}$ \\
\hline $\mathrm{LB}+\mathrm{CaO}$ & $27,5 \mathrm{Aa}$ & $27,6 \mathrm{Aa}$ & 27,6 & $-6,5$ & $-4,1$ & $-5,3 \mathrm{~B}$ \\
\hline Médias & 26,3 & 24,0 & 25,2 & $-9,2 \mathrm{a}$ & $-8,3 a$ & $-8,8$ \\
\hline CV (\%) & & & 4,89 & & & 18,91 \\
\hline
\end{tabular}

Médias seguidas da mesma letra, maiúscula na coluna e minúscula na linha, não diferiram (P>0,05) estatisticamente pelo teste Tukey.

${ }^{1}$ Diferença entre o teor na abertura e na ensilagem. CV = coeficiente de variação. 
O óxido de cálcio é um aditivo alcalinizante e pode alterar a população de microrganismos presente na silagem por reduzir a atividade de água e elevar o pH (Santos et al., 2008). Segundo Jobim et al. (2007), a atividade de água refere-se à medição da concentração de solutos em água e seus efeitos sobre a atividade química da água. Neste sentido, pode-se inferir que a presença de óxido de cálcio na ensilagem da cana-de-açúcar in natura ou queimada reduziu a atividade de água, restringindo o crescimento de leveduras, principais responsáveis pela redução do conteúdo de MS nas silagens de cana-de-açúcar, mesmo considerando que, com a utilização de óxido de cálcio, houve adição de água via aplicação do aditivo superior à utilizada com o inoculante. Siqueira et al. (2009) constataram que silagens de cana-deaçúcar in natura ou queimada tratadas com $1 \%$ de $\mathrm{NaOH}$ na MS apresentaram maiores valores de MS se comparadas às silagens controle. Em média, foram observadas 2,5 unidades percentuais a mais nas silagens tratadas.

Os valores de $\mathrm{pH}$ não diferiram entre as silagens produzidas com cana-de-açúcar in natura ou queimada $(\mathrm{P}>0,05)$. Nas silagens tratadas com óxido de cálcio, com ou sem $L$. buchneri, os valores de $\mathrm{pH}$ foram superiores aos das demais (Tabela 3). A análise dos valores de $\mathrm{pH}$ deve ser feita juntamente com a variação do $\mathrm{pH}$, pois a avaliação isolada dos dados de pH pode resultar em interpretação errônea. Nas silagens tratadas com óxido de cálcio, foram maiores as variações de $\mathrm{pH}$, isto é, apesar dos maiores valores de $\mathrm{pH}$, nessas silagens a redução do $\mathrm{pH}$ foi mais intensa.

$\mathrm{O}$ valor de $\mathrm{pH}$ final depende do $\mathrm{pH}$ inicial, da capacidade tampão, da concentração de ácidos orgânicos, entre outros fatores. Além do maior pH inicial, a forragem, quando é tratada com aditivos alcalinizantes, como o $\mathrm{NaOH}$ ou o óxido de cálcio, apresenta capacidade tampão superior à das silagens não-tratadas (Santos et al., 2008; Siqueira et al., 2011). Castrillón et al. (1978) trataram a cana-de-açúcar com $4 \%$ de $\mathrm{NaOH}$ na matéria seca e observaram que as silagens controle tiveram $1,6 \%$ de ácido lático, enquanto as tratadas apresentaram 12,2\%. Mesmo com essa alta produção de ácido lático, as silagens tratadas apresentaram pH de 4,41, enquanto as não-tratadas 4,12. Fato semelhante foi observado por Santos et al. (2008), que observaram, em relação às silagens controles $(3,46)$, maiores valores de $\mathrm{pH}$ naquelas tratadas com óxido de cálcio na proporção de 1\% da matéria natural $(4,09)$, embora as silagens tratadas com óxido de cálcio tenham apresentado 3,66\% de ácido lático e as controle apenas 2,00\% na MS. Dessa forma, pode-se inferir que, neste estudo, as silagens tratadas com óxido de cálcio possivelmente apresentaram maiores concentrações de ácido lático.

A adição de L. buchneri na ensilagem do milho e sorgo (Filya, 2003), capins (Driehuis et al., 2001) e grãos úmidos (Taylor \& Kung Junior, 2002) geralmente propicia valores de $\mathrm{pH}$ mais elevados que nas silagens controle, devido à capacidade desse aditivo de converter ácido lático em ácido acético e 1,2 propanodiol (Oude Eferink et al., 2001). No entanto, em silagens de cana-de-açúcar, valores de $\mathrm{pH}$ mais elevados normalmente não são observados com a utilização do L. buchneri (Siqueira et al., 2007a; Pedroso et al., 2007; Santos et al., 2008). Uma possível explicação para esse fato é a baixa capacidade tampão da cana-deaçúcar e seu alto conteúdo de carboidratos solúveis, que, em condições de baixas concentrações de ácidos orgânicos, são suficientes para redução do $\mathrm{pH}$. Comprovando esse fato, autores como Pedroso et al. (2005) e Evangelista et al. (2009) constataram redução do $\mathrm{pH}$ de silagens de cana-deaçúcar a valores inferiores a 3,8 com sete e três dias, respectivamente.

Nas silagens de cana-de-açúcar in natura, as maiores perdas por gases foram observadas nas silagens $L$. buchneri, que diferiram daquelas tratadas com óxido de cálcio com e sem L . buchneri. Já as silagens controles não diferiram das demais (Tabela 4). Nas silagens de cana-de-açúcar queimada, as perdas por gases foram maiores $(\mathrm{P}<0,05)$ naquelas que não receberam óxido de cálcio (sem e com $L$. buchneri).

Tabela 3 - Valores de pH final e variação do pH de silagens de cana-de-açúcar in natura ou queimada tratadas com óxido de cálcio (CaO) e/ou L. buchneri

\begin{tabular}{|c|c|c|c|c|c|c|}
\hline \multirow{3}{*}{ Aditivos } & \multicolumn{3}{|c|}{$\mathrm{pH}$ final } & \multicolumn{3}{|c|}{ Variação do $\mathrm{pH}^{1}$} \\
\hline & \multicolumn{2}{|c|}{ Cana-de-açúcar } & \multirow{2}{*}{ Médias } & \multicolumn{2}{|c|}{ Cana-de-açúcar } & \multirow{2}{*}{ Médias } \\
\hline & In natura & Queimada & & In natura & Queimada & \\
\hline Controle & 3,7 & 3,7 & $3,7 \mathrm{~B}$ & $-2,0$ & $-1,8$ & $-1,9 \mathrm{~A}$ \\
\hline Lactobacillus buchneri (LB) & 3,7 & 3,6 & $3,6 \mathrm{~B}$ & $-2,0$ & $-2,0$ & $-2,0 \mathrm{~A}$ \\
\hline Óxido de cálcio $(\mathrm{CaO})$ & 4,1 & 4,1 & $4,1 \mathrm{~A}$ & $-8,2$ & $-7,5$ & $-7,9 \mathrm{~B}$ \\
\hline $\mathrm{LB}+\mathrm{CaO}$ & 4,1 & 4,1 & $4,1 \mathrm{~A}$ & $-8,1$ & $-8,0$ & $-8,0 \mathrm{~B}$ \\
\hline Médias & $3,9 a$ & $3,9 a$ & 3,88 & $-5,1 \mathrm{a}$ & $-4,8 \mathrm{a}$ & $-5,0$ \\
\hline CV (\%) & & & 3,68 & & & 6,01 \\
\hline
\end{tabular}

Médias seguidas da mesma letra, maiúscula na coluna e minúscula na linha, não diferiram $(\mathrm{P}>0,05)$ estatisticamente pelo teste Tukey.

${ }^{1}$ Diferença entre o teor na abertura e na ensilagem. CV = Coeficiente de variação. 
Nas silagens tratadas com óxido de cálcio, não houve diferença significativa entre a cana-de-açúcar in natura ou queimada $(\mathrm{P}>0,05)$, enquanto nas controle e com L. buchneri, a queima propiciou elevação da perda por gases $(\mathrm{P}<0,05)$.

Siqueira et al. (2011) observaram redução da perda por gases em silagens de cana-de-açúcar tratadas com $\mathrm{NaOH}$. A explicação exposta foi que no metabolismo de bactérias homofermentativas, a fermentação de glicose com síntese de ácido lático não gera produção de $\mathrm{CO}_{2}$. A inclusão de $\mathrm{NaOH}$, possivelmente propiciou aumento no teor de ácido lático, conforme foi observado nos estudos de Castrillón et al. (1978) e Santos et al. (2008), devido ao estímulo de desenvolvimento de bactérias homofermentativas. Nesse cenário, pode-se inferir que a redução das perdas por gases foi resultado do aumento da população de bactérias homofermentativas que consumiram com maior eficiência os carboidratos solúveis, reduzindo principalmente a atuação das leveduras.

Maiores perdas por gases em silagens de cana-deaçúcar queimada podem ser atribuídas a maior atuação de leveduras nessas condições, devido a elevação da disponibilidade de substratos. Ao se realizar a queima ocorre concentração dos açúcares solúveis e também pode-se inferir que com a retirada da palha a quantidade proporcional de açúcares foi aumentada. Bernardes et al. (2007) observaram elevação da população de leveduras de 2,2 para 2,7 ufc/g de silagem e da concentração de etanol de 6,5 para 7,3\% da MS em silagens de cana-de-açúcar queimada em relação às de cana-de-açúcar in natura. Segundo os autores, a presença de açúcares redutores (glicose e frutose) pode facilitar a fermentação alcoólica pelas leveduras, pois, segundo Walker (1998) algumas espécies possuem invertase, enzima capaz de degradar a sacarose, enquanto outras cepas, por não possuírem a enzima, ficariam limitadas à fermentação desse dissacarídeo. Assim, com a presença de elevados teores de glicose e frutose, duas fontes de carbono capazes de serem facilmente fermentadas, as silagens produzidas com cana-de-açúcar queimada podem apresentar maiores teores de etanol.

Esperava-se que as silagens tratadas com L. buchneri apresentassem menores perdas por gases, devido à ação deste inoculante bacteriano sobre fungos e leveduras. A proposta de utilização do L . buchneri na ensilagem de canade-açúcar foi feita por Nussio et al. (2003), com base em resultados positivos obtidos no controle de leveduras durante a exposição aeróbia de silagens de milho e sorgo. A base de atuação do L. buchneri se dá pelo acúmulo de ácido acético que por sua vez tem efeito inibitório no crescimento de leveduras (Moon, 1983). Todavia, esse efeito não foi constatado e uma das possíveis explicações é a dose utilizada. Segundo Kleinschmit \& Kung Júnior (2006), doses acima de $1 \times 10^{5} \mathrm{ufc} / \mathrm{g}$ de forragem fresca apresentam maior efeito sobre o controle de leveduras que doses inferiores a essas. Nos trabalhos desenvolvidos nos Estados Unidos e na Europa com outras plantas forrageiras, a dose comumente utilizada é a $5 \times 10^{5} \mathrm{ufc} / \mathrm{g}$ de forragem fresca, ou seja, 10 vezes a dose utilizada na presente pesquisa, que é a recomendada no Brasil.

Nas silagens de cana-de-açúcar in natura não foram constatados efeitos dos aditivos sobre a produção de efluente $(\mathrm{P}>0,05)$. As silagens tratadas com $\mathrm{CaO}$ com ou sem LB apresentaram menor produção de efluente comparada as demais $(\mathrm{P}<0,05)$.

Os valores observados de produção de efluentes nas silagens de cana-de-açúcar in natura encontram-se dentro da variação constatada na literatura, que vai de 7,0 kg/t MN (Pedroso et al., 2007) a 76,2 kg/t MN (Siqueira et al., 2007a).

Nas silagens de cana-de-açúcar queimada, ocorre maior produção de efluente, possivelmente devido à retirada da palha, que, além de reduzir o teor de matéria seca da forragem, também pode atuar como aditivo sequestrante de umidade da silagem (Siqueira et al., 2011).

Nas silagens de cana-de-açúcar queimada, houve efeito do Lactobacillus buchneri em reduzir a produção de

Tabela 4 - Perdas por gases (\% MS total) e produção de efluente, kg por tonelada de matéria natural (kg/t MN) de silagens de cana-deaçúcar in natura ou queimada tratadas com óxido de cálcio $(\mathrm{CaO})$ e/ou L. buchneri

\begin{tabular}{|c|c|c|c|c|c|c|}
\hline \multirow{3}{*}{ Aditivos } & \multicolumn{3}{|c|}{ Perdas por gases (\%) } & \multicolumn{3}{|c|}{ Produção de efluente $(\mathrm{kg} / \mathrm{t} \mathrm{MN})$} \\
\hline & \multicolumn{2}{|c|}{ Cana-de-açúcar } & \multirow{2}{*}{ Médias } & \multicolumn{2}{|c|}{ Cana-de-açúcar } & \multirow{2}{*}{ Médias } \\
\hline & In natura & Queimada & & In natura & Queimada & \\
\hline Controle & $23,3 \mathrm{ABb}$ & $36,0 \mathrm{Aa}$ & 29,7 & $15,0 \mathrm{Ab}$ & $90,5 \mathrm{Aa}$ & 52,8 \\
\hline Lactobacillus buchneri (LB) & $27,4 \mathrm{Ab}$ & $36,2 \mathrm{Aa}$ & 31,8 & $14,7 \mathrm{Ab}$ & $74,1 \mathrm{Ba}$ & 43,9 \\
\hline Óxido de cálcio (CaO) & $20,5 \mathrm{Ba}$ & $18,9 \mathrm{Ba}$ & 19,7 & $14,6 \mathrm{Ab}$ & $40,5 \mathrm{Ca}$ & 27,6 \\
\hline $\mathrm{LB}+\mathrm{CaO}$ & $20,7 \mathrm{Ba}$ & $17,1 \mathrm{Ba}$ & 18,9 & $19,6 \mathrm{Ab}$ & $36,3 \mathrm{Ca}$ & 27,9 \\
\hline Médias & 23,0 & 27,1 & 25,0 & 15,7 & 60,4 & 38,0 \\
\hline CV (\%) & & & 13,11 & $\mathrm{CV}(\%)$ & & 15,48 \\
\hline
\end{tabular}

Médias seguidas da mesma letra, maiúscula na coluna e minúscula na linha, não diferiram $(\mathrm{P}>0,05)$ estatisticamente pelo teste Tukey. $\mathrm{CV}=$ coeficiente de variação. 
efluentes. Schmidt (2008), em revisão sobre aditivos na ensilagem da cana-de-açúcar, constatou que, de 13 estudos avaliados, três apresentaram redução da produção de efluente devido ao uso do L. buchneri. A utilização de óxido de cálcio na ensilagem da cana-de-açúcar queimada, segundo a revisão de Schmidt (2008) apresentou potencial de redução da produção de efluente, pois em quatro dos seis estudos houve efeito positivo com a utilização deste aditivo. Siqueira et al. (2011) também observaram redução da produção de efluente em silagens de cana-de-açúcar queimada e tratada com $\mathrm{NaOH}(1 \%)$. Visualmente as silagens tratadas com aditivos alcalinos apresentam extravasamento celular, porém não ocorre percolação do líquido.

Nas silagens de cana-de-açúcar in natura houve diferença da recuperação de matéria seca (RMS) nas silagens tratadas com óxido de cálcio com e sem $L$. buchneri nas tratadas apenas com L. buchneri, sendo que as controle não diferiram de nenhuma das demais (Tabela 5). Nas silagens de cana-de-açúcar queimada a diferenciação se deu em função da presença ou não do óxido de cálcio, o que está de acordo com os dados de perdas por gases e produção de efluente (Tabela 4).

A presença do óxido de cálcio com ou sem associação ao L. buchneri nas silagens de cana-de-açúcar queimada,

Tabela 5 - Recuperação da matéria seca (\%) de silagens de canade-açúcar in natura ou queimada tratadas com óxido de cálcio $(\mathrm{CaO})$ e/ou L. buchneri

\begin{tabular}{|c|c|c|c|}
\hline \multirow{3}{*}{ Aditivos } & \multicolumn{3}{|c|}{ Recuperação da matéria seca (\%) } \\
\hline & \multicolumn{2}{|c|}{ Cana-de-açúcar } & \multirow{2}{*}{ Médias } \\
\hline & In natura & Queimada & \\
\hline Controle & $63,5 \mathrm{ABa}$ & $46,8 \mathrm{Bb}$ & 55,2 \\
\hline Lactobacillus buchneri (LB) & $61,2 \mathrm{Ba}$ & $54,2 \mathrm{Ba}$ & 57,7 \\
\hline Óxido de cálcio (CaO) & $71,3 \mathrm{Aa}$ & $75,5 \mathrm{Aa}$ & 73,4 \\
\hline $\mathrm{LB}+\mathrm{CaO}$ & 73,7Аa & 79,3Аа & 76,5 \\
\hline Médias & 67,4 & 64,0 & 65,7 \\
\hline CV (\%) & & & 6,97 \\
\hline
\end{tabular}

transformaram silagens com alto potencial de perdas em silagens semelhantes às de cana-de-açúcar in natura com óxido de cálcio. Avaliando silagens de cana-de-açúcar in natura, Santos et al. (2008) constataram redução das perdas de matéria seca em aproximadamente 17 unidades percentuais, atribuí-se esse efeito a inibição do crescimento de microrganismos indesejáveis, como as leveduras que consomem carboidratos e geram etanol e $\mathrm{CO}_{2}$.

A observação de alta recuperação de MS apresenta-se como um dos principais desafios relacionados à ensilagem da cana-de-açúcar. Siqueira et al. (2005) demonstraram que as perdas ocorridas durante a fermentação da cana-deaçúcar representam $80 \%$ das perdas, quando consideradas as fases de fermentação e aerobiose.

Perdas de matéria seca da ordem de $30 \%$ são facilmente encontradas na literatura na ensilagem de cana-de-açúcar pura ou com aditivos que não foram eficientes no controle das leveduras (Pedroso et al., 2005; Siqueira et al., 2007a; Santos et al., 2008; Sousa et al., 2008; Siqueira et al., 2011). No entanto, perdas próximas a 50\% não são relatadas na literatura, e assim há que se considerar que neste caso trata-se de silagens de cana-de-açúcar queimada e na maioria dos estudos avaliou-se apenas a cana-de-açúcar in natura. Com base, nos dados obtidos por Bernardes et al. (2007) e Siqueira et al. (2011) pode-se considerar a cana-deaçúcar queimada mais propensa às perdas de MS, quando essas não são devidamente controladas por meio da utilização de aditivos.

Os teores de proteína bruta (PB) foram maiores nas silagens de cana-de-açúcar queimada em comparação com as de cana-de-açúcar in natura $(\mathrm{P}<0,05)$. Em relação aos aditivos maiores teores foram observados nas silagens controle e nas L. buchineri $(\mathrm{P}<0,05)$ (Tabela 6). Pode-se atribuir a elevação dos teores de PB ao consumo de carboidratos solúveis por leveduras durante a fermentação, acarretando assim a elevação numérica na proporção de proteína no conteúdo celular. Evangelista et al. (2009)

Tabela 6 - Teores médios de proteína bruta (PB) (\% MS), na abertura e variação do teor de proteína bruta de silagens de cana-de-açúcar in natura ou queimada tratadas com óxido de cálcio $(\mathrm{CaO})$ e/ou L. buchneri

\begin{tabular}{|c|c|c|c|c|c|c|}
\hline \multirow{3}{*}{ Aditivos } & \multicolumn{3}{|c|}{ PB } & \multicolumn{3}{|c|}{ Variação no teor de $\mathrm{PB}^{1}$} \\
\hline & \multicolumn{2}{|c|}{ Cana-de-açúcar } & \multirow{2}{*}{ Médias } & \multicolumn{2}{|c|}{ Cana-de-açúcar } & \multirow{2}{*}{ Médias } \\
\hline & In natura & Queimada & & In natura & Queimada & \\
\hline Controle & 3,07 & 4,00 & $3,53 \mathrm{~A}$ & 0,44 & 1,07 & $0,76 \mathrm{~A}$ \\
\hline Lactobacillus buchneri (LB) & 3,05 & 3,73 & $3,39 \mathrm{~A}$ & 0,34 & 0,76 & $0,55 \mathrm{~A}$ \\
\hline Óxido de cálcio (CaO) & 2,51 & 2,76 & $2,63 \mathrm{~B}$ & 0,48 & 0,22 & $0,35 \mathrm{~A}$ \\
\hline $\mathrm{LB}+\mathrm{CaO}$ & 2,37 & 2,51 & $2,44 \mathrm{~B}$ & 0,35 & 0,24 & $0,30 \mathrm{~A}$ \\
\hline Médias & $2,75 b$ & $3,25 a$ & 3,00 & $0,40 \mathrm{a}$ & $0,58 \mathrm{a}$ & 0,49 \\
\hline CV (\%) & & & 10,29 & & & 69,6 \\
\hline
\end{tabular}

Médias seguidas da mesma letra, maiúscula na coluna e minúscula na linha, não diferiram ( $\mathrm{P}>0,05)$ estatisticamente pelo teste Tukey.

${ }^{1}$ Diferença entre o teor na abertura e na ensilagem. CV = coeficiente de variação. 
observaram elevação da PB de 1,7 a 2,7\% da ensilagem aos 60 dias de fermentação.

A correta interpretação deve ser baseada na variação da $\mathrm{PB}$, mas neste estudo não foi observada diferença significativa $(\mathrm{P}>0,05)$ entre as silagens avaliadas e esse resultado pode ser atribuído ao alto coeficiente de variação desta variável (69,6\%). Todavia, numericamente a tendência de variação no teor de PB foi a mesma observada para os teores de PB.

As silagens de cana-de-açúcar in natura apresentaram maiores teores de FDN em comparação às de cana-deaçúcar queimada $(\mathrm{P}<0,05)$ (Tabela 7$)$. Em relação aos aditivos as silagens com óxido de cálcio sem $L$. buchneri apresentaram valores intermediários e as com óxido de cálcio e L. buchneri tiveram os menores teores de FDN. Esses resultados podem, a princípio, ser atribuídos às perdas ocorridas durante a fermentação, mas são dependentes dos teores no momento da ensilagem.

Nas silagens de cana-de-açúcar in natura ou queimada, óxido de cálcio, com ou sem $L$. buchineri, reduziu significativamente a variação da $\operatorname{FDN}(\mathrm{P}<0,05)$, o que pode estar relacionado à solubilização da hemicelulose, devido à ação da alcalinidade do óxido de cálcio. Outra explicação é a redução do consumo de carboidratos solúveis, proporcionando menor elevação da FDN (Figura 1).

Com base nos resultados da recuperação da MS (Tabela 5), pode-se atribuir que efetivamente o óxido de cálcio, com ou sem a presença do LB, manteve as silagens de cana-de-açúcar in natura ou queimada mais próximas aos teores fibrosos encontrados no momento da abertura (Figura 1). Esse fato pode ser atribuído ao possível controle da população de leveduras pela alteração da pressão osmótica.

A digestibilidade verdadeira in vitro da matéria seca (DVIVMS) nas silagens de cana-de-açúcar in natura foi maior naquelas tratadas com óxido de cálcio com e sem L. buchneri (Tabela 8). Nas silagens de cana-de-açúcar

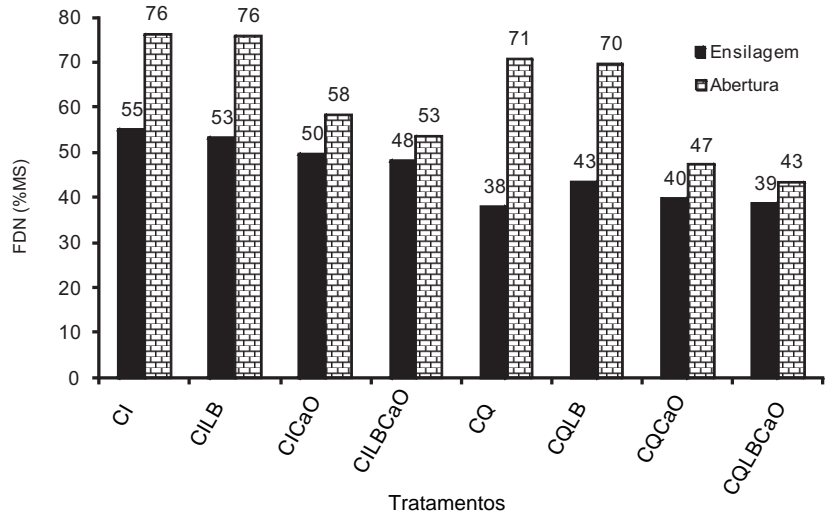

CI: cana-de-açúcar in natura sem aditivo, CILB: cana-de-açúcar in natura com L. buchneri, CICaO: cana-de-açúcar in natura com óxido de cálcio, CILBCaO: cana-de-açúcar in natura com L. buchneri e óxido de cálcio, CQ: cana-deaçúcar queimada sem aditivo, CQLB: cana-de-açúcar queimada com L. buchneri, CQCaO: cana-de-açúcar queimada com óxido de cálcio e CQLBCaO cana-deaçúcar queimada com $L$. buchneri e óxido de cálcio.

Figura 1 - Teores de fibra em detergente neutro na ensilagem e na abertura de silagens de cana-de-açúcar.

queimada, os maiores valores foram observados também na presença de óxido de cálcio com e sem L. buchneri: os valores intermediários foram observados nas silagens com L. buchneri e os menores nas silagens controles. A maior digestibilidade nas silagens com óxido de cálcio pode ser atribuída à solubilização dos componentes fibrosos (Tabela 7) e também à redução das perdas de MS (Tabela 5).

A queima não promoveu diferença significativa $(\mathrm{P}>0,05)$ apenas nas silagens sem aditivos (Tabela 8$)$. As silagens de cana-de-açúcar queimada apresentaram maior digestibilidade in vitro da MS em comparação às de canade-açúcar in natura. Conforme foi comentado na discussão dos teores de PB, a correta interpretação deve ser baseada na variação da DVIVMS. Nas silagens de cana-de-açúcar in natura, as variações na DVIVMS foram reduzidas nas silagens com óxido de cálcio com e sem L. buchneri, o mesmo ocorreu nas silagens de cana-de-açúcar queimada (Tabela 8). A manutenção da digestibilidade a valores próximos ao da ensilagem pode ser considerada uma

Tabela 7 -Teores médios de fibra em detergente neutro (FDN) (\% MS) e variação do teor de FDN de silagens de cana-de-açúcar in natura ou queimada tratadas com óxido de cálcio $(\mathrm{CaO})$ e/ou L. buchneri

\begin{tabular}{|c|c|c|c|c|c|c|}
\hline \multirow{3}{*}{ Aditivos } & \multicolumn{3}{|c|}{ FDN } & \multicolumn{3}{|c|}{ Variação no teor de $\mathrm{FDN}^{1}$} \\
\hline & \multicolumn{2}{|c|}{ Cana-de-açúcar } & \multirow{2}{*}{ Médias } & \multicolumn{2}{|c|}{ Cana-de-açúcar } & \multirow{2}{*}{ Médias } \\
\hline & In natura & Queimada & & In natura & Queimada & \\
\hline Controle & 76,0 & 70,1 & $73,4 \mathrm{~A}$ & $20,9 \mathrm{Ab}$ & $32,9 \mathrm{Aa}$ & 26,9 \\
\hline Lactobacillus buchneri (LB) & 75,9 & 69,7 & $72,8 \mathrm{~A}$ & $22,7 \mathrm{Aa}$ & $26,3 \mathrm{Ba}$ & 24,5 \\
\hline Óxido de cálcio (CaO) & 58,2 & 47,2 & $52,7 \mathrm{~B}$ & $8,5 \mathrm{Ba}$ & $7,4 \mathrm{Ca}$ & 7,9 \\
\hline $\mathrm{LB}+\mathrm{CaO}$ & 53,5 & 43,3 & $48,4 \mathrm{C}$ & $5,5 \mathrm{Ba}$ & $4,8 \mathrm{Ca}$ & 5,1 \\
\hline Médias & $65,9 a$ & $57,7 \mathrm{~b}$ & 61,8 & 14,4 & 17,8 & 16,1 \\
\hline CV (\%) & & & 2,74 & & & 13,44 \\
\hline
\end{tabular}

Médias seguidas da mesma letra, maiúscula na coluna e minúscula na linha, não diferiram (P>0,05) estatisticamente pelo teste Tukey.

${ }^{1}$ Diferença entre o teor na abertura e na ensilagem. CV = coeficiente de variação. 
característica muito desejável, pois todo processo de conservação de forragem ocasiona perdas qualitativas.

Neste estudo, a variação na DVIVMS foi condizente com os dados de alteração da FDN na ensilagem para a abertura da silagem (Figura 1), com a recuperação da matéria seca (Tabela 5) e os valores de FDN dos tratamentos, pois existe alta correlação negativa entre digestibilidade e teor de FDN na cana-de-açúcar (Pedroso et al., 2005). Além disso, nas silagens tratadas com óxido de cálcio com e sem L. buchneri, pode ter havido maior preservação de carboidratos não-fibrosos da cana-de-açúcar, que são a porção mais digestível dessa forragem (Corrêa et al., 2003).
A análise em conjunto de todas as variáveis de perdas e das variações da composição química possibilitou a construção do dendrograma resultante da análise de agrupamento por método hierárquico (Figura 2). No dendrograma, observa-se a formação de dois grupos: um grupo (grupo 1) contendo silagens com óxido de cálcio e outro grupo (grupo 2) contendo as silagens sem óxido de cálcio. Os resultados da análise de agrupamento por método não hierárquico confirmam esta classificação. O grupo 1 apresentou maior recuperação de MS e variação do $\mathrm{pH}$ e menores perdas por gases, produção de efluente e variação nos conteúdos de MS, FDN, PB e DVIVMS em comparação ao grupo 2 (Figura 3).

Tabela 8 - Valores médios de digestibilidade verdadeira in vitro da matéria seca (DVIVMS) (\% MS) e variação da DVIVMS de silagens de cana-de-açúcar in natura ou queimada tratadas com óxido de cálcio (CaO) e/ou L. buchneri

\begin{tabular}{|c|c|c|c|c|c|c|c|}
\hline \multirow{3}{*}{ Aditivos } & \multicolumn{3}{|c|}{ DVIVMS } & & \multicolumn{3}{|c|}{ Variação da DVIVMS ${ }^{1}$} \\
\hline & \multicolumn{2}{|c|}{ Cana-de-açúcar } & \multirow{2}{*}{ Médias } & \multirow[t]{2}{*}{ Aditivos } & \multicolumn{2}{|c|}{ Cana-de-açúcar } & \multirow{2}{*}{ Médias } \\
\hline & In natura & Queimada & & & In natura & Queimada & \\
\hline Controle & $32,6 \mathrm{Ba}$ & 35,9 Ca & 34,3 & Controle & $-20,3 \mathrm{Ab}$ & $-30,7 \mathrm{Aa}$ & $-25,5$ \\
\hline $\mathrm{LB}^{1}$ & $36,8 \mathrm{Bb}$ & $50,0 \mathrm{Ba}$ & 43,4 & $\mathrm{LB}^{1}$ & $-18,8 \mathrm{Aa}$ & $-13,7 \mathrm{Bb}$ & $-16,2$ \\
\hline $\mathrm{CaO}$ & $52,6 \mathrm{Ab}$ & $63,0 \mathrm{Aa}$ & 57,8 & $\mathrm{CaO}$ & $-5,2 \mathrm{Ba}$ & $-2,99 \mathrm{Ca}$ & $-4,1$ \\
\hline $\mathrm{LB}+\mathrm{CaO}$ & $55,6 \mathrm{Ab}$ & $62,0 \mathrm{Aa}$ & 58,8 & $\mathrm{LB}+\mathrm{CaO}$ & $-3,4 \mathrm{Ba}$ & $-1,91 \mathrm{Ca}$ & $-2,7$ \\
\hline Médias & 44,4 & 52,7 & 48,6 & Médias & $-12,0$ & $-12,3$ & $-12,1$ \\
\hline CV (\%) & & & 5,82 & CV (\%) & & & 20,3 \\
\hline
\end{tabular}

Médias seguidas da mesma letra, maiúscula na coluna e minúscula na linha, não diferiram (P>0,05) estatisticamente pelo teste Tukey.

${ }^{1}$ Diferença entre o teor na abertura e na ensilagem. CV = coeficiente de variação.

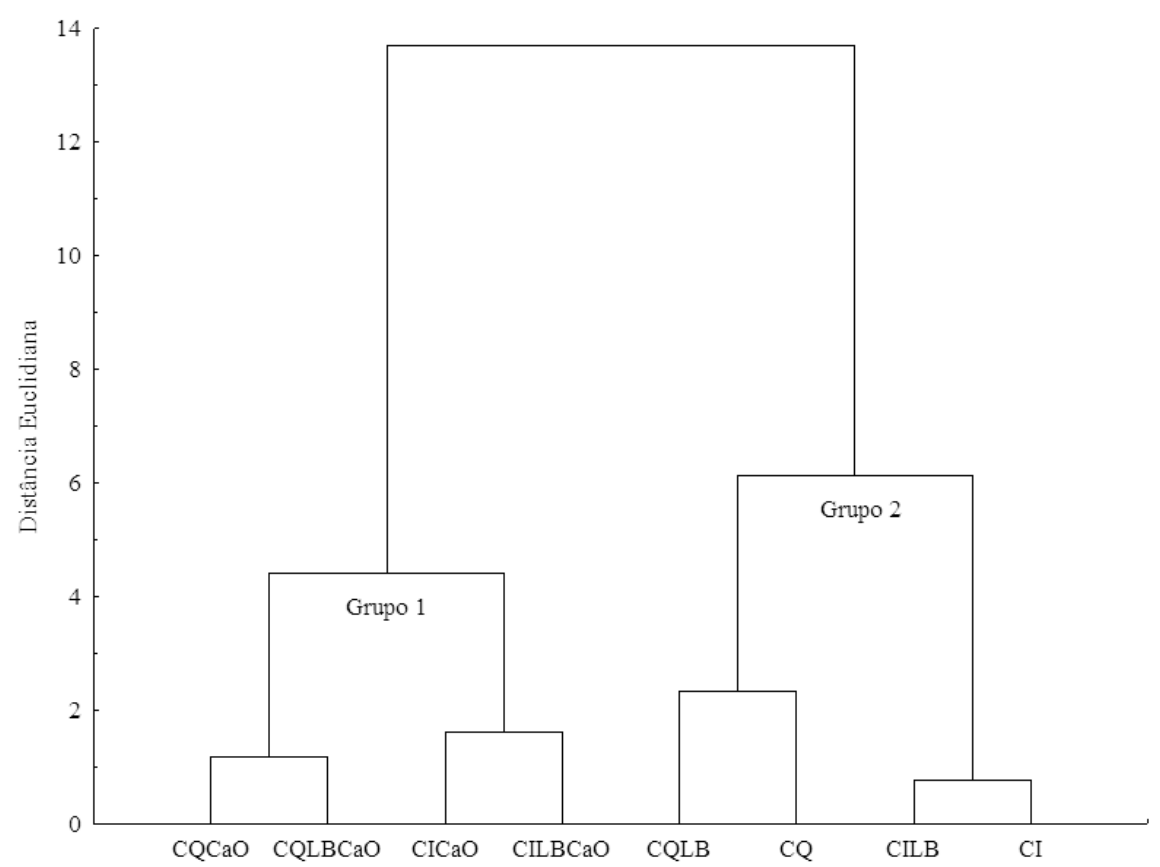

CI: cana in natura; CILB: cana in natura com Lactobacillus buchneri; CICaO: cana in natura com óxido de cálcio; CILBCaO: cana in natura com L. buchneri e óxido de cálcio; CQ: cana queimada, CQLB: cana queimada com L. buchneri; CQCaO: cana queimada com óxido de cálcio; CQLBCaO: cana queimada com L. buchneri e óxido de cálcio.

Figura 2 - Dendrograma da análise de agrupamento por método hierárquico das avaliações de perdas e das variações composição química de silagens de cana-de-açúcar. 
Uma análise de variância univariada aplicada aos centroides de cada grupo mostrou que as variáveis produção de efluente e variação no conteúdo de PB não discriminam esses grupos, pois não apresentaram diferenças estatisticamente significantes $(\mathrm{P}>0,05)$. O grupo 1 ficou caracterizado pelas silagens tratadas com óxido de cálcio, independentemente de serem provenientes de cana-de-açúcar in natura ou queimada e inoculadas ou não com $L$. buchneri. $\mathrm{O}$ grupo 2 ficou caracterizado por conter silagens de cana-deaçúcar sem óxido de cálcio.
A análise de componentes principais permitiu a construção do biplot bidimensional formado pelos dois primeiros componentes principais (Figura 4). As variáveis que mais discriminaram no primeiro componente principal, em ordem de importância, foram: recuperação de MS (correlação 0,99); variação no conteúdo de FDN (correlação -0,99); PG (correlação -0,95), VMS (correlação -0,93), VDVIVMS (correlação-0,93), VPH (correlação 0,90), VPB (correlação-0,89) e EFLU (correlação-0,67). As variáveis com correlações positivas indicam associação da variável

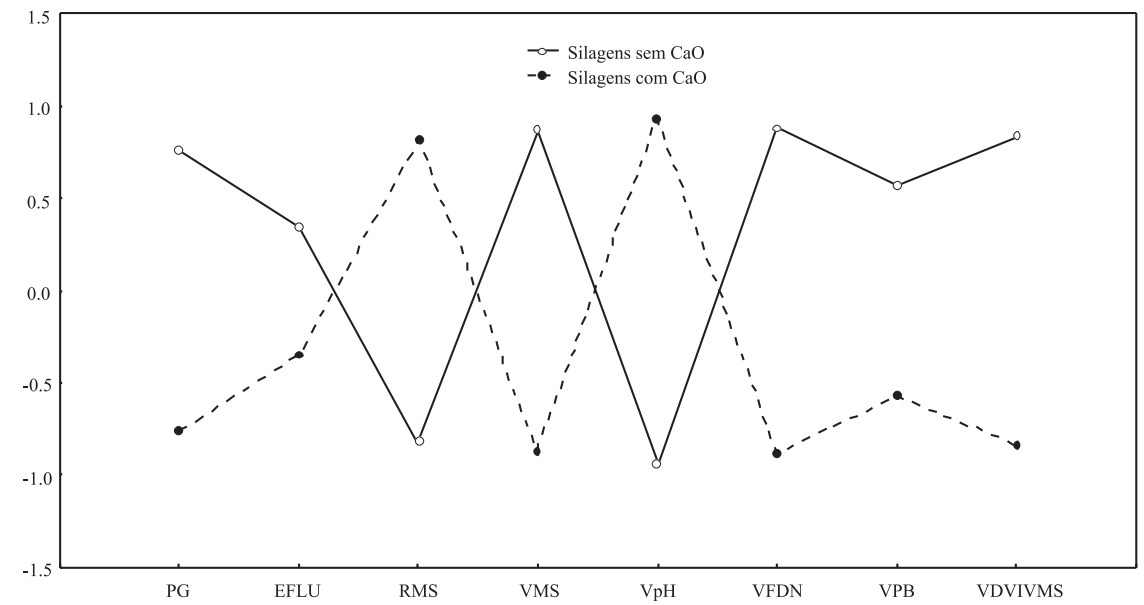

PG: perdas por gases; EFLU: produção de efluente; RMS: recuperação de matéria seca; VMS: variação da matéria seca; VpH: variação do pH; VFDN: variação do FDN; VPB: variação da proteína bruta; e VDVIVMS: variação da digestibilidade verdadeira in vitro da matéria seca

Figura 3 - Perfil dos grupos 1 e 2 construídos pelo algoritmo K-means utilizando as avaliações de perdas e as variações composição química de silagens de cana-de-açúcar.

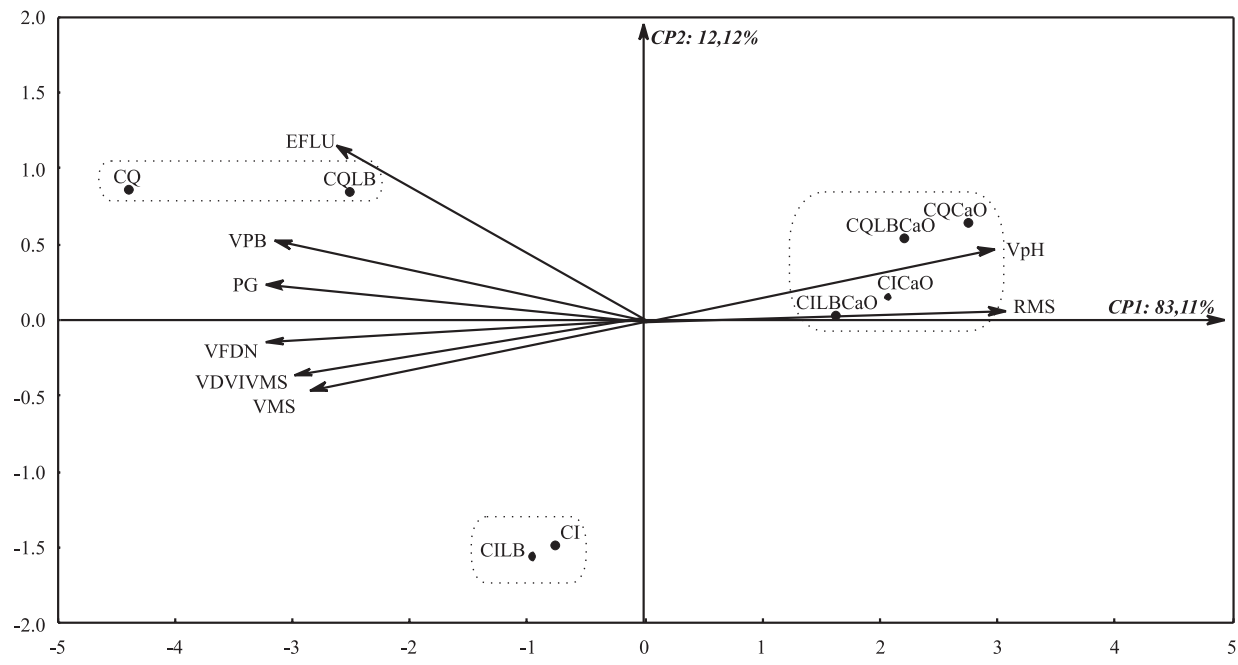

CI: cana in natura, CILB: cana in natura com Lactobacillus buchneri, CICaO: cana in natura com óxido de cálcio, CILBCaO: cana in natura com L. buchneri e óxido de cálcio, CQ: cana queimada, CQLB: cana queimada com L. buchneri, CQCaO: cana queimada com óxido de cálcio, CQLBCaO: cana queimada com L. buchneri e óxido de cálcio PG: perdas por gases; EFLU: produção de efluente; RMS: recuperação de matéria seca; VMS: variação da matéria seca; VpH: variação do pH; VFDN: variação do FDN; VPB: variação da proteína bruta; e VDVIVMS: variação da digestibilidade verdadeira in vitro da matéria seca.

Figura 4 - Distribuição dos tratamentos em função das perdas e das variações da composição química de silagens de cana-de-açúcar nos componentes principais 1 e 2 . 
com as amostras localizadas à direita no eixo horizontal (CP1) e aquelas com correlações negativas indicam associação com as amostras localizadas à esquerda eixo horizontal (CP1). Assim, como os tratamentos do grupo 1 estão localizados à direita de CP1, houve dependência com $\mathrm{VpH}$ e recuperação da MS, enquanto o grupo 2, por se localizar à esquerda de $\mathrm{CP} 1$, está associado às maiores perdas durante o processo de conservação.

O grupo 1 foi discriminado por apresentar as maiores recuperações de matéria seca, que, neste caso, pode-se associar a maior produção de ácido lático (Santos et al., 2008), devido à elevada variação do $\mathrm{pH}$. A produção de ácido lático não gera perdas quantitativas, por não ter síntese de $\mathrm{CO}_{2}$ (McDonald et al., 1991). Atribui-se também à redução das perdas ao controle de leveduras, que, durante a fermentação, consomem carboidratos solúveis e geram etanol e $\mathrm{CO}_{2}$. Teoricamente, o óxido de cálcio controlaria o crescimento da população de leveduras devido à mudança na pressão osmótica. Com a redução do consumo de carboidratos solúveis, diminui a concentração da PB e da FDN e consequentemente os valores da digestibilidade mantêm-se próximos ao da forragem no momento da ensilagem.

Quanto ao segundo componente principal, somente a variável EFLU apresentou poder discriminatório (correlação 0,71 ), indicando que as silagens de cana queimada têm maior produção de efluente. Pode-se, desta forma, fazer uma subseparação dos tratamentos sem óxido de cálcio em dois grupos, de modo que a principal diferença entre eles está na produção de efluentes, sendo que as demais variáveis apresentaram baixa correlação neste componente principal. Em silagens de cana-de-açúcar, as perdas por efluente não possuem grande expressão, devido às elevadas perdas por gases.

\section{Conclusões}

O óxido de cálcio reduz as perdas e as alterações na composição química na ensilagem de cana-de-açúcar in natura ou queimada. O Lactobacillus buchneri apenas atuou nas silagens de cana-de-açúcar queimada. Silagens de cana-de-açúcar queimada foram mais propensas às perdas que as de cana-de-açúcar in natura.

\section{Referências}

ASSOCIATION OF OFFICIAL ANALYTICAL CHEMISTS - AOAC. Official methods of analysis of the Association of Analytical Chemists. 15.ed. Arlington: 1990. 1117p.

BALIEIRO NETO, G.; SIQUEIRA, G.R.; REIS, R.A. et al. Óxido de cálcio como aditivo na ensilagem de cana-de-açúcar. Revista Brasileira de Zootecnia, v.36, n.5, p.1231-1239, 2007.
BERNARDES, T.F.; REIS, R.A.; SIQUEIRA, G.R. et al. Avaliação da queima e da adição de milho desintegrado com palha e sabugo na ensilagem de cana-de-açúcar. Revista Brasileira de Zootecnia, v.36, n.2, p.269-275, 2007.

CASTRILLÓN, M.V.; SHIMADA, A.S.; CALDERÓN, F.M. Manipulación de la fermentación en ensilajes de caña de azúcar y su valor alimenticio para borregos. Técnica Pecuária do México, v.35, p.48-55, 1978.

CORRÊA, C.E.S.; PEREIRA, M.N.; OLIVEIRA, S.G. et al. Performance of Holstein cows fed sugarcane or corn silages of different grain textures. Scientia Agricola, v.60, p.221-229, 2003.

DESCHAMPS, F.C. Implicações do período de crescimento na composição química e digestão dos tecidos de cultivares de capim elefante. Revista Brasileira de Zootecnia, v.28, p.1178-1189, 1999.

DRIEHUIS, F.; OUDE ELFERINK, S.J.W.H.; Van WIKSELAAR, P.G. Fermentation characteristics and aerobic stability of grass silage inoculated with Lactobacillus buchneri, with or without homofermentative latic acid bacteria. Grass and Forage Science, v.56, p.330-343, 2001.

EVANGELISTA, A.R.; SIQUEIRA, G.R.; LIMA, J.A. et al. Perfil fermentativo de silagens de cana-de-açúcar com e sem inclusão de milho desintegrado com palha e sabugo. Revista Brasileira de Zootecnia, v.38, p.20-26, 2009.

FERRAUDO, A.S. Técnicas de análise multivariada. 2.ed. São Caetano do Sul: Statsoft South America, 2006. 88p.

FILYA, I. The Effect of Lactobacillus buchneri and Lactobacillus plantarum on the fermentation, aerobic stability, and ruminal degradability of low dry matter corn and sorghum silages. Journal of Dairy Science, v.85, p.3575-3581, 2003.

HAIR, J.F.; ANDERSON, R.E.; TATHAM, R.L. et al. Análise multivariada de dados. 5.ed. Porto Alegre: Bookman, 2005. 593p.

JOBIM, C.C.; NUSSIO, L.G.; REIS, R.A. et al. Avanços metodológicos na avaliação da qualidade da forragem conservada. Revista Brasileira de Zootecnia, v.36, p.101-120, 2007 (supl. especial).

KAISER, H.F. The varimax criterion for analytic rotation in factor analysis. Psychometrika, v.23, p.187-200, 1958.

KLEINSCHMIT, D.H.; KUNG JUNIOR, L. A Meta-analysis of the effects of Lactobacillus buchneri on the fermentation and aerobic stability of corn and grass and small-grain silages. Journal of Dairy Science, v.89, n.10, p.4005-4013, 2006.

KUNG JUNIOR, L.; GRIEVE, D.B.; THOMAS, J.W. et al. Added ammonia or microbial inoculant for fermentation and nitrogenous compounds of alfalfa ensiled at various percents of dry matter. Journal of Dairy Science, v.67, n.2 p.299-306, 1984.

McDONALD, P.; HENDERSON, A.R.; HERON, S.J.E. The biochemistry of silage. 2.ed. Marlow: Chalcomb Publications, 1991. 340p.

MOON, N.J. Inhibition of the growth of acid tolerant yeasts by acetate, lactate and propionate and their synergistic mixtures. Journal of Applied Bacteriology, v.55, n.3, p.453-460, 1983.

NUSSIO, L.G.; SCHMIDT, P. Tecnologia de produção e valor alimentício de silagens de cana-de-açúcar. In: SIMPÓSIO SOBRE PRODUÇÃO E UTILIZAÇÃO DE FORRAGENS CONSERVADAS, 2., 2004, Maringá. Anais... Maringá: UEM/CCA/DZO, 2004. p.1-33.

NUSSIO, L.G.; SCHMIDT, P.; PEDROSO, A.F. Silagem de cana-deaçúcar. In: PEIXOTO, A.M; MOURA, J.C.; Da SILVA, S.C. et al. (Eds.) Simpósio de pastagens. Piracicaba: FEALQ/USP/ ESALQ, 2003. p.100-150.

OUDE ELFERINK, S.J.W.H.; KROONEMAN, J.; GOTTSCHAL, J.C. et al. Anaerobic conversion of lactic acid to acetic acid and 1,2-propanediol by Lactobacillus buchneri. Applied and Environmental Microbiology, v.67, n.1, p.125-132, 2001.

PEDROSO, A.F.; NUSSIO, L.G.; PAZIANI, S.F. et al. Fermentation and epiphytic microflora dynamics in sugar cane silage. Scientia Agricola, v.62, n.5, p.427-432, 2005.

PEDROSO, A.F.; NUSSIO, L.G.; LOURES, D.R.S. et al. Efeito do tratamento com aditivos químicos e inoculantes bacterianos nas perdas e na qualidade de silagens de cana-de-açúcar. Revista Brasileira de Zootecnia, v.36, n.3, p.558-564, 2007. 
PIRES, A.J.V.; REIS, R.A.; CARVALHO, G.G.P. et al. Bagaço de cana-de-açúcar tratado com hidróxido de sódio. Revista Brasileira de Zootecnia, v.35, n.3, p.953-957, 2006 (supl.).

ROBERTSON, J.B.; VAN SOEST, P.J. The detergent system of analysis and its application to human foods. In: JAMES, W.P.T.; THEANDER, O. (Eds.) The analysis of dietary fiber in food. New York: Marcel Dekker, 1981. p.123-158.

SANTOS, M.C.; NUSSIO, L.G.; MOURÃO, G.B. et al. Influência da utilização de aditivos químicos no perfil da fermentação, no valor nutritivo e nas perdas de silagens de cana-de-açúcar. Revista Brasileira de Zootecnia, v.37, n.9, p.1555-1563, 2008.

SCHMIDT, P. Aditivos químicos e biológicos no tratamento de canade-açúcar para alimentação de bovinos. In: JOBIM, C.C.; CECATO, U.; CANTO, M.W. (Eds.) Produção e utilização de forragens conservadas. Maringá: Masson, 2008. p.117-152.

SIQUEIRA, G.R.; BERNARDES, T.F.; REIS, R.A. Instabilidade aeróbia de silagens: efeitos e possibilidades de prevenção. In: REIS, R.A.; SIQUEIRA, G.R.; BERTIPAGLIA, L.M.A. et al. (Eds.) Volumosos na produção de ruminantes. Jaboticabal: Funep, 2005. p.25-60.

SIQUEIRA, G.R.; REIS, R.A.; SCHOCKEN-ITURRINO, R.P. et al. Associação entre aditivos químicos e bacterianos na ensilagem de cana-de-açúcar. Revista Brasileira de Zootecnia, v.36, n.4, p.789-798, 2007b.

SIQUEIRA, G.R.; REIS, R.A.; SCHOCKEN-ITURRINO, R.P. et al. Perdas de silagens de cana-de-açúcar tratadas com aditivos químicos e bacterianos. Revista Brasileira de Zootecnia, v.36, n.6, p.2000-2009, 2007a (supl.).
SIQUEIRA, G.R.; REIS, R.A.; SCHOCKEN-ITURRINO, R.P. et al. Influência da queima e de aditivos químicos e bacterianos na composição química de silagens de cana-de-açúcar. Archivos de Zootecnia, v.57, n.221, p.43-54, 2009.

SIQUEIRA, G.R.; REIS, R.A.; SCHOCKEN-ITURRINO, R.P. et al. Queima e aditivos químicos e bacterianos na ensilagem da cana-deaçúcar Revista Brasileira de Zootecnia, v.40, n.8, p.1651-1661, 2011.

SNEATH, P.H.A.; SOKAL, R.R. Numerical taxonomy. San Francisco: W.H.Freeman, 1973. 573p.

SOUSA, D.P.; MATTOS, W.R.S.; NUSSIO, L.G. Efeito de aditivo químico e inoculantes microbianos na fermentação e no controle da produção de álcool em silagens de cana-de-açúcar. Revista Brasileira de Zootecnia, v.37, n.9, p.1564-1572, 2008.

STATISTICAL ANALYSES SYSTEM - SAS. SAS User's guide. Statistics, Version 8.01 Edition. Cary: 1999. (CD-ROM)

STATSOFT, Inc. (2004). STATISTICA (Data analysis software system), version 7. Disponível em: <www.statsoft.com.>. Acesso em: 10 jan. 2010 .

TAYLOR, C.C.; KUNG JUNIOR, L. The effect of Lactobacillus buchneri 40788 on the fermentation and aerobic stability of high moisture corn in laboratory silos. Journal of Dairy Science, v.85, n.6, p.1526-1532, 2002.

VALADARES FILHO, S.C.; PAULINO, P.V.R.; MAGALHÃES, K.A Exigências nutricionais de zebuínos e tabelas de composição de alimentos BR-corte. Viçosa, MG: UFV, 2006. 142p.

WALKER, G.M. Yeast physiology and biotechnology. London: Wiley Editorial Offices, 1998. 350p. 